\title{
Training for innovation in Spain
}

Àngela Janer-Hidalgo, Anna Ciraso-Calí, Carla Quesada-Pallarès, Pilar Pineda-Herrero ～24.09.2015 10:44:47

News

Authors: Anna Ciraso-Calí, Pilar Pineda-Herrero, Carla Quesada-Pallarès, Àngela Janer-Hidalgo

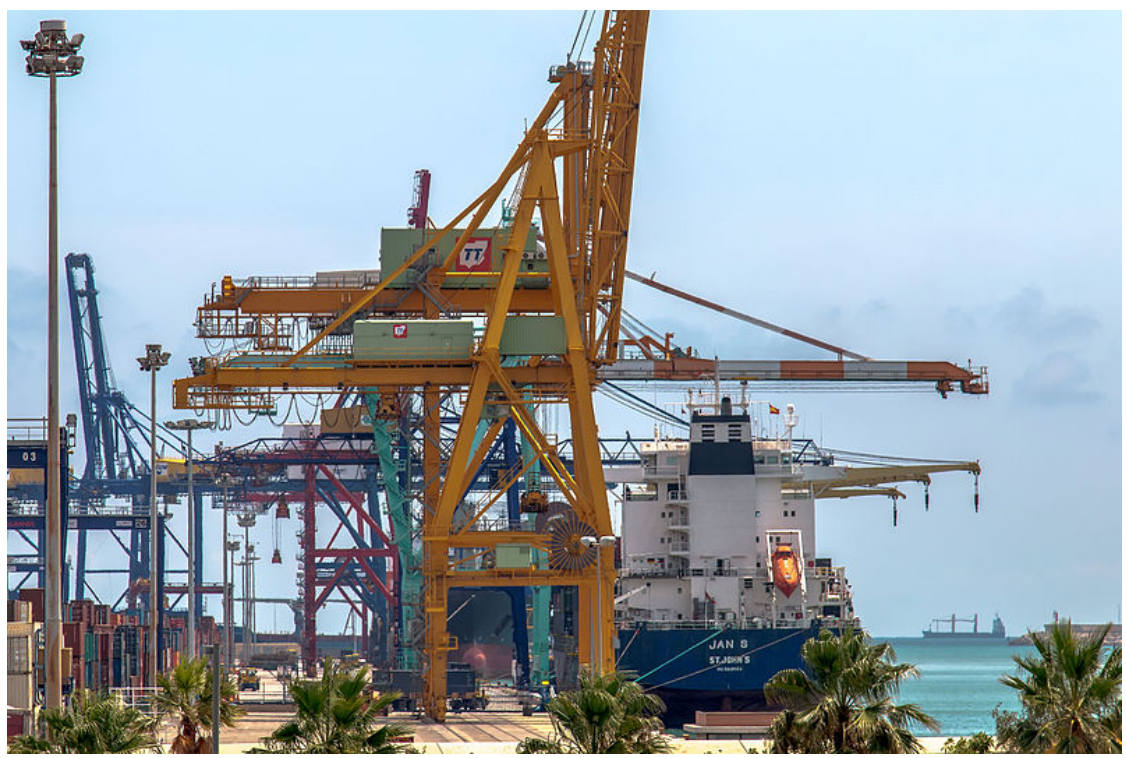

Training aids innovation, which in turn is crucial to the economy. The Port of Valencia in mid-day bustle. / Photo: Mike1979 Russia

\section{Abstract}

The capacity for innovation of an organisation largely depends on its ability to acquire and develop new knowledge. Training is particularly important in this process, as it allows employees to constantly acquire new competences. This study provides a preliminary picture of the situation of training for innovation in Spain, and identifies the characteristics of companies offering training for innovation.

Results show that 35.3\% of Spanish companies undertake innovation processes and $22.3 \%$ offer training related to these innovation processes. For the $82 \%$ of these companies training helped the innovation process, so training is an important tool for innovative changes.

\section{Introduction}

For organisations, being innovative can make the difference between staying active in the market or being overtaken by competitors. Some studies indicate that boosting the innovative capacity of enterprises by developing the skills of workers increases business results and contributes to economic recovery. In this context, it is very important that organisations develop the knowledge and skills of their employees to drive change and to build innovative capacity (CEDEFOP, 2012).

In this paper we focus on academic discussion about the development of innovation processes and the training role to develop new knowledge in organisations and to generate innovation capacity in its members. We describe and analyse the characteristics of training for innovation in Spanish companies, in order to better understand how this training takes place and further develop HRD discussion on this specific topic.

In the current economic situation, Spain has the challenge of improving its financial situation and to prepare the labour market to meet the new demands and changes required. Innovation is a need for Spanish companies in order to be competitive, and training is a way to enhance innovation.

Surveys such as Eurostat (Statistical Office of the European Communities, 2013) stated that the Spanish business fabric is mainly composed of SMEs (99.8\%). Large companies invest important amounts of money on training and this training is often connected with innovation processes; but only $30 \%$ of SMEs (SME's organising public funded training) offer training to their employees (Fundación Tripartita para la Formación para el Empleo, 2015), and training contents are rarely connected with innovations in the organisation.

In this context, our research questions are: is innovation somehow connected with training in Spanish companies? When companies in Spain run innovations, do they help the process with training? How is training for innovation organised? What are their characteristics?

We conducted a cross-sectional study with a stratified random sampling design based on two variables: company size and sector; the final sample consisted of 400 Spanish companies, and the technique we used was a telephone survey.

The paper is a part of a larger study, focused on assessing the effectiveness of training for innovation and funded by the Fundación Tripartita para la 
Formación para el Empleo. Here we only present the results of the survey, in which training managers were asked about innovation processes in their organisations and the role and characteristics of training for innovation.

\section{Innovation and training in organisations}

Innovation in organisations is understood as a process whose goal is to develop changes, either in the form of products or processes that add value and allow the organisation to gain a competitive edge in the market and to ensure their growth and survival (Ridderstrale and Nordström, 2008; Bruton, 2011; Fang et al., 2011).

Ellstrom (2010), remarks that a new process is considered an innovation when it is possible to demonstrate its contribution towards furthering the goals of the organisation.

Several studies show that innovation contributes to improving the quality of organisations' products and services, helping to increase of sales (Jiménez and Sanz, 2008; Soriano and Huarng, 2013; Löfsten, 2014).

Learning organisations facilitate innovation processes. These organisations are characterized by their human resources management aimed at facilitating innovative processes. Innovation capability enables organisations to create, manage and maintain knowledge (Kontoghiorghes et al., 2005; Rasmussen, 2012).

Innovation, unlike creativity, is a planned process (Axelrod, 2008), that should involve the acquisition and application of knowledge in order to achieve a creative idea. According to Smith, Courvisanos and McEachern (2011), knowledge and access to knowledge are some of the necessary elements for innovation to take place; therefore, knowledge management is crucial for innovation processes.

Several studies have shown that organisational learning plays a very important role when it comes to generating innovation in organisations, as it allows constant learning of new skills (De la Fuente 2005; Ellstrom 2010; Rasiah 2011; Yu Yuan et al., 2011).

Although much of the learning that occurs in organisations can be labelled as informal (Cross, 2007), incidental (Marsick and Watkins, 1990) or workplace learning (Tynjälä, 2008), it is crucial to explore the role of formal training during innovation: it can be an essential part of organisations' investment in order to carry on the planned change, in economic terms along with human resources and time.

Furthermore, the ability to innovate has a direct relationship with the ability to acquire and apply knowledge (Tidd et al., 2005; Courvisanos, 2007; Soriano and Huarng, 2013). Training has therefore gained a strategic importance for organisations as a key element in the innovation process (Martínez-Ros and Orfila-Sintes, 2012). Innovations need the development of new professional competences whether through training activities or informal learning processes; thus the relation between innovation, training and learning is beyond doubt.

Stemming from this, 'training for innovation' refers to training that is intended to generate innovations in the organisation; in other words, training that develops the necessary skills to allow trainees to innovate in their work (Pineda -dir.-, 2013). As Smith et al. say, 'training is crucial for innovation, creating organisational cultures and management capabilities which stimulate and sustain innovation' (2011, p.12). It is therefore a different concept than innovative training, which is related to methodological innovations.

Edralin (2007) considers that innovation takes place if there is an appropriate context in which organisational structure, culture and human resources practices such as training are geared towards innovation processes.

On the one hand, the key aspects are related to those necessary skills for people to participate in an innovation process, such as critical thinking, initiative, effective communication, access and information analysis (Edralin, 2007; Burton, 2011; Fluellen 2011). Other authors also consider other key skills in innovation processes: creativity, generating new ideas, promoting the sense of belonging to an organisation (Bruton, 2011; Rasmussen, 2012), and sharing the resolution of problems (Heiskanen and Heiskanen, 2011).

On the other hand, the most appropriate methodological characteristics of training for innovation are, above all, teamwork, inter-disciplinary efforts, games, trial and error, and information and communication technology (DelnTra, 2008; Kirarh, 2008; Burton, 2011); and the importance of horizontal relationships between trainers and trainees, as well as a self-directed learning style (Bransford and Cocking, 1999; DelnTra, 2008; Ho, 2010).

The aim of this paper is to describe and analyse the characteristics of training for innovation in Spain, such as training features (contents, modality, methodology, assessment, location and schedule of training, type of trainer, and the agents in charge of designing and promoting training) and innovation

\section{Methodology}

The study followed a cross-sectional design with an exploratory approach; in order to achieve our aim, we used a quantitative technique to collect the data. This section explains the study methodology.

\subsection{Sample}

We conducted an intentional non-probabilistic sampling among the companies that participated in state-funded training in Spain during the year 2011. The statistical population was made up of $\pm 273,609$ companies. Applying a margin of error of $5 \%$ and a $95 \%$ level of confidence yielded a sample size of 384 companies, thus obtaining a representative sample of the population. The final sample was composed of 400 valid surveys, which were answered in 
full.

Next, we used a random stratified sampling design based on two variables: company size -micro-enterprise (68.3\%), small business (24.5\%), medium-sized business (6\%) and large business (1.3\%) - and the economic sector -agriculture (23.8\%), commerce (17.8\%), building (9\%), hospitality (15\%), industry (33.8\%), and other services (0.8\%)-.

It is worth noting that Spanish companies are mostly represented by small and medium enterprises (SMEs) which means that a lot of them do not have a position specially design for a training manager or do not a training programme. In this case, most of the companies use specialised companies that provide training activities to these types of business.

In the distribution of surveyed individuals (see Table 1), we found that the majority were clerks (37.8\%) -most of them women (78.1\%)- and human resources managers (11.8\%), out of which $66 \%$ were women. This might point towards a feminisation of this profession. Nevertheless, over two thirds (69.8\%) of managers (24\%) are men; which is concordant with the masculinisation of senior leadership positions, which are held by women in only $11.7 \%$ of cases in Spain (EADA/ICSA, 2014).

Table 1

Table 1. Distribution by gender of surveyed people in different positions.

Only 5.2\% of the surveyed people work almost exclusively in training management, and $81.7 \%$ spend less than a quarter of their working day on training. It is possible to analyse this data in the light of the size of the companies we have analysed: the majority are micro-enterprises (with no more than 10 workers).

In these companies, our results show that $97.5 \%$ of people in charge of training also carry out other tasks in the company, and only $2.6 \%$ of them spend more than $75 \%$ of their time on training. Nevertheless, even in large companies (with over 250 workers), over half of the people surveyed (60\%) also handled tasks not related to training.

The people in charge of training we surveyed had worked in the same company for an average of 10 years (standard deviation of 8 years), and almost 9 years in their current position (standard deviation of 7 years). Therefore, we can state that professionals in charge of training have a vast amount of experience and stability in their position, even though they also carry out tasks other than managing training.

\subsection{Instruments and techniques}

We used telephone surveys by CATI system (Computer Assisted Telephone Interviewing); it is a fast technique both for contacting and collecting information with a higher answer rate that needs fewer interviewers (Fernández, 2004).

The dimensions and variables included in the surveys of training managers are listed in Table 2. Moreover, to help training managers to contextualize the innovation questions, we used this question. Is your organisation currently pursuing innovation processes? If so, is the innovation a planned process of change that leads to an improvement in your company or organisation?'

Table 2

Table 2. Dimensions and variables in the survey to training managers.

The survey included 37 questions: 14 answered from a list; 13 multiple choice questions; 10 short open-ended questions. We conducted a pilot survey to estimate the required time (15 minutes), items comprehension and whether the answer codes were assigned correctly.

\subsection{Analysing the data}

We extracted the results to a matrix using the SPSS V17 Inc. computer programme and analysed them according to the types of variables used, via descriptive analyses. Analyses involved the sample profile, the innovation processes in companies, and the characteristics of prior training actions that were related to innovation processes.

\section{Results}

Out of a total of 400 companies we interviewed, only 141 were carrying out some kind of innovation process; among them, 89 carried out training actions related to these processes, and 63 of these companies were rating these training actions. The following figure shows the number of cases included in the different sub-groups of the sample.

When analysing companies involved in innovation processes, we found that $35.3 \%$ were developing some kind of innovation process at the time they were surveyed, whereas $62 \%$ of training managers stated that their organisations were not carrying out any such programs. 
It is noteworthy that $2.8 \%$ of respondents did not know whether or not innovation processes were being carried out in their company. These respondents, therefore, lacked sufficient knowledge. The people who did not know whether or not innovation processes were being carried out mostly worked in microenterprises (from 1 to 10 workers) in the services sector in secretary positions and carried out other tasks as well as training.

\section{Figure 1}

Figure 1. Sub-groups in the sample of surveyed companies.

After presenting a brief description of the sample, we report the key data about organisations' innovation processes and training, which accompanies the innovation process. Moreover, more detailed information about 89 training activities (one for each company) related to innovations is provided.

\subsection{Innovation processes in organisations}

A study of the types of innovation processes being undertaken (Figure 2) reveals that over $50 \%$ of companies focus on innovations in the field of technology (68.1\%), processes (63.8\%), goods or services (60.3\%), or communications channels $(53.9 \%)$.

\section{Figure 2}

Figure 2. Types of innovation process being carried out.

In $14.9 \%$ of cases, innovation processes only referred to a single type of change in the organisation. Furthermore, $12.1 \%$ of the companies were involved in innovation processes in all the fields considered (infrastructure, technology, culture, processes, goods or services, and the communications channels of a given organisation). It is also significant that, among those organisations that are carrying out changes related to technology, $63.8 \%$ are also involved in innovation related to organisation, and $60.3 \%$ are implementing changes in the goods or services offered.

We found that, in those companies and organisations where innovation processes were being carried out, $63.1 \%$ stated that they had undertaken some kind of training related to these processes. Some reasons are: the training actions were not deemed necessary to accompany the process of change; they did plan a training programme but it had not been carried out; lack of resources; training managers; and interest in training related to the innovation.

\subsection{Training activities related to innovation processes}

In this section we describe a specific training activity of each company ( $n=89)$ : this activity was described in detail by the training manager as related to an innovation process.

Time at which 'training for innovation' activities were carried out: most respondents (53.9\%) stated that activities were performed synchronously, i.e. during the development of the innovation process. Nevertheless, $32.6 \%$ of them were carried out before the innovation; $18 \%$ just at the beginning; $6.7 \%$ just at the end; and $9 \%$ after the innovation process. This shows that training managers understand that 'training for innovation' can take place at any point of the process, even before it has started or after it has ended; however, they tend to plan training activities along with the innovation processes so they can be intertwined.

Training activities: $55.1 \%$ are related to job-specific technical skills; $38.2 \%$ to computing and office technology skills; $34.8 \%$ to creativity and innovation skills; $31.5 \%$ to management and administration skills; $27 \%$ to problem solving skills. Furthermore, training activities identified as 'innovation training' by managers are multidisciplinary as they cover more than one type of contents, especially technical skills and creativity (24.72\% of training activities).

Delivery style: $57.3 \%$ were carried out face-to-face, $23.6 \%$ were e-learning and $19.1 \%$ were blended-learning. $48.5 \%$ of face-to-face and blended-learning activities were performed outside the company whereas in $44.1 \%$ of cases, activities were delivered on the company's own premises. Sessions were only carried out in the workplace in $20.6 \%$ of cases.

Agents to promote 'training for innovation': $47.2 \%$ of the activities stem from management team followed by human resources department (20.2\%), workers themselves (19.1\%) and other departments (15.7\%). Training department only promoted training in $13.5 \%$ of cases, and trade unions do not appear as a promoting agent. In the vast majority of cases (88.8\%) training is promoted by a single agent (see Figure 3).

Figure 3

Figure 3. Agents that promote training for innovation.

Target group: qualified workers are the most important target group for training for innovation, as $65.2 \%$ of training activities are meant for them. In $47.2 \%$ of cases activities are intended for specialists, and in $33.7 \%$ of cases they are intended for intermediate staff. Nearly half of the training activities targets are people with different positions in the organisational hierarchy, mostly qualified workers and specialists (28.1\%), and qualified and non-qualified workers (25.8\%).

Reasons to participate in training: $52.8 \%$ of the respondents stated that they attended training on their own initiative. This could represent a high 
motivation to learn and high probability to apply the acquired knowledge; however, in $34.8 \%$ of cases, participation in training was mandatory (see figure 4). It important to remember that this data reflects training managers' view on the reasons why workers participate (or not) in training.

\section{Figure 4}

Figure 4. Reasons that led people to participate in training for innovation.

Training design: $80 \%$ of training activities were designed by a third-party company; $20.2 \%$ were designed by the company's own training manager or specialist; and, in $12.4 \%$ of cases, the internal trainer designed the training. The analysis of multiple answers reveals that the majority of training activities $(87.6 \%)$ were designed exclusively by one of these three agents, especially by external agents; on the other hand, only $9 \%$ of the companies collaborated with an external company to design training.

A high involvement of external agents in designing training could lead to a reduced compatibility between the training on offer and the organisation's needs, specifically regarding the necessity to acquire skills related to the innovation process to which the training is related.

Methodologies: A wide array of methodologies is used for training, as can be seen in figure 5 . Trainers use presentations and demonstrations, problem solving and case studies in over $80 \%$ of cases. Mentoring, tutoring, simulations and teamwork are also common. Simulations were used in $74.2 \%$ of the described cases, as well as coaching (58.4\%) in the same vein; teamwork (65.2\%) should allow for questions and debates to take place, as well as collaborative thinking. The least used method in these training activities was games, in $29.2 \%$ of cases, even though gamification is an essential resource in experiential learning, overall when it is linked to innovation.

\section{Figure 5}

Figure 5. Methods used in training for innovation.

Assessment: $70.8 \%$ of respondents stated that some type of evaluation was carried out. Only $2.2 \%$ of the respondents did not have enough information about whether or not training was rated in their organisation. Nonetheless, training evaluation is a complex process which depends on the level of shows that the most frequently assessed aspect of training is the learning achieved by the trainees (74.6\%), followed by training transfer to the workplace (52.4\%) and trainees' satisfaction with the training (50.8\%). Impact, as well as return on the training investment (ROI), was only examined in $27 \%$ and $15.9 \%$ of cases, respectively.

\section{Figure 6}

Figure 6. Levels evaluated in training for innovation.

An analysis of the multiple answers reveals that all levels were only evaluated in $12.7 \%$ of cases, whereas almost half of the training activities were only evaluated on a single level. This seems to indicate that the evaluation carried out is not very thorough or exhaustive and that the information gathered about their efficacy is not enough to decide whether or not good investment for the company is taking place.

Training managers were asked to rate the results of the training activity they were explaining, on a scale from 0 to 10 . As it is shown in table 3 , all aspects are rated highly. The most highly rated aspect is the impact of training on the organisation, with an average of 8.25 . This data informs that even 'training for innovation' activities are not usually assessed on their impact; respondents think that these actually have a positive impact on their organisation.

However, if impact is not measured, how accurate is this perception? On the other hand, the worst rated item is trainee's satisfaction, although the average answer (7.73) is still quite high.

\section{$\underline{\text { Table } 3}$}

Table 3. Rating levels for training related to the innovation process, and assessments.

According to $82 \%$ of respondents, training influenced the innovation process, whereas only $12.4 \%$ stated that it did not. Out of these $82 \%$, $34.2 \%$ rated the quality of this influence with a mean of 8 points on a scale from 0 to 10 . Figure 7 shows that the distribution of these assessments does not follow a normal curve with asymmetric positive skewness, displaying an accumulation of values on the right side of the graph. In other words, high ratings are the most common, with mean of 7.61 (standard deviation 1.37), stating a high influence of training over innovation.

\section{Figure 7}

Figure 7. Influence of training on the innovation process. 
consequences for the company. None of the respondents mentioned negative or highly negative consequences caused by training for innovation. Then, training is seen as an innovation facilitator being possible the label of 'training for innovation'; however, its influence and consequences seem not be assessed formally so the accuracy of this perception needs to be proven.

\section{Discussion}

'Doing things today better than yesterday' is the underlying premise of any innovation process. However, it is sometimes necessary to accompany this process with training to guarantee that employees have the necessary tools and resources required to carry it out.

Throughout this paper we present a picture of 'training for innovation' in Spanish companies based on a telephone survey to a representative sample of 400 training professionals. It is a cross-sectional study so the aim is not to identify the causality between training activities and innovation but to analyse how and when training is provided to enhance an innovation in Spanish organisations.

The need to carry out this study was twofold. On the one hand, modern organisations use procedural, technological, human, etc., innovation processes to become competitive powers on the market. Indeed, Jiménez and Sanz (2008, p. 1216) stated that 'innovation affects a firm's performance'. Training is an important strategy to develop the competencies needed in an innovation process (Pineda -dir-, 2013). It is therefore necessary to know if firms use training related to innovation processes to ensure optimum efficiency and how they use it.

Results show that about $97 \%$ of the respondents have information about the development of innovation processes in the companies they were working for, and about training related to them. This suggests that innovation processes are shared, open and transparent within the companies. Considering that the $98.8 \%$ of the representative Spanish sample belongs to SME companies -i.e. that their economical and human resources dedicated to innovation could be smaller than in large companies-, only 35\% of Spanish organisations carry out innovation processes, and those are mostly geared towards technology.

Out of these companies, $63 \%$ conducted planned training activities related to these processes of change. Among those that did not carry out training, the reasons that stand out are that it was not considered necessary as well as a lack of resources.

However, Spanish 2012 PIAAC data (OECD, 2013) show that at least 74\% of currently employees who do not participate in training activities are involved in some kind of informal learning, whether learning from co-workers, learning by doing or keeping up to date with new products. This indicates that even in the $27 \%$ of companies which do not offer planned training activities related to innovation, it is very likely that learning processes are occurring at an informal level. As an emerging research perspective, researchers should focus on the relationship between informal learning and innovation processes from the employees' point of view.

Regarding the 'training for innovation' features, the theoretical framework points out which features should be included in training related to an innovatior process, based on the skills required from people who participate in an innovation process, methodological characteristics and the relationship between the trainer and the trainee in such programs. Indeed, results on teaching and learning methods are consistent with the literature. On the one hand, we found that some of the most widely used methods in 'training for innovation' activities are simulations (74.2\%), problems (86.5\%) and cases (80.9\%). These methods are suitable to accompany innovations, particularly regarding the organisations' processes (Das and Joshi, 2007; Burton, 2011).

On the other hand, experts on innovation agree that one of the main features of 'training for innovation' is methodological diversity (Burton, 2011; DelnTra, 2008; Kirah, 2008). Answers provided by the training managers confirm this statement, as more than $90 \%$ of these activities used five or more different training methodologies.

The figures reveal that $78 \%$ of 'training for innovation' activities are carried out physically or with a b-learning approach. This type of training favours faceto-face encounters between the trainer and the trainees, thus encouraging a horizontal trainer-trainee relationship as pointed out by Ho (2010), DelnTra (2008) and Bransford and Cocking (1999).

Finally, only $17 \%$ of these 'training for innovation' programmes are evaluated. However, $82 \%$ of respondents think that training influenced the innovation process, on an average rating of 7.61 (from 0 to 10). This confirms the results obtained by De Winne and Sels (2010), which showed that the development of human capital, both employers' and employees', is an important determinant of innovation as a strategic plan for the company. Likewise, over $95 \%$ of respondents stated that these training activities had positive or very positive consequences on the organisation in general.

This article shows the general and representative trend of Spanish companies regarding innovation process and training related to them. These can be useful both for researchers and practitioners. For researchers, results point out the need to explore the role played by not only training but also learning, in every stage of the innovation process. It may be appropriate to use a qualitative methodology and a $360^{\circ}$ assessment in order to study it in depth in order to overcome the study's limitation.

For instance, a longitudinal multiple case studies of some of these companies would help both practitioners and researchers to understand how an innovation process is developed, its design, delivery and impact, as well as how training and learning are related to this process. Contextual variables would also help us to establish specific action plans to improve innovation processes in Spanish organisations accompanied with proper learning activities.

For practitioners, the importance of learning activities related to innovation processes is highlighted. They should not only establish training programmes before or during the innovation process but also learning activities in order to develop key skills that guarantee the participation and maintenance of the innovation after the process finishes. 


\section{References}

Axelrod, A. (2008). Edison on innovation: 102 lessons in creativity for business and beyond. San Francisco, CA: John Wiley \& Sons.

Bransford, J. D., Brown, A. L. \& Cocking, R. R. (1999). How people learn. Brain, Mind, Experience, and School, National Research Council. Washington: D.C.

Bruton, D. (2011). Learning creativity and design for innovation. International Journal of Technology and Design Education, 21(3), 321-333.

CEDEFOP (2012). Learning and innovation in enterprises. Research paper. Luxembourg: Publications Office of the European Union.

Cross, J. (2007). Informal learning: Rediscovering the natural pathways that inspire innovation and performance. San Francisco: Pfeiffer.

Courvisanos, J. (2007). The ontology of innovation: human agency in the pursuit of novelty. History of Economics Review, 45, 41-59.

Das, S. R., \& Joshi, M. P. (2007). Process innovativeness in technology services organizations: Roles of differentiation strategy, operational autonomy and risk-taking propensity. Journal of Operations Management, 25(3), 643-660.

De la Fuente, R. (2005). Formación continua como factor de innovación y calidad. In Frías, M.S., \& López, B. (Eds.), I Jornadas La calidad en el actual sistema educativo (61-78). Universidad de Burgos.

De Winne, S., \& Sels, L. (2010). Interrelationships between human capital, HRM and innovation in Belgian start-ups aiming at an innovation strategy. The International Journal of Human Resource Management, 21(11), 1863-1883.

DelnTra. (2008). Report on the barriers and gaps hindering the deployment of innovative training methodologies in European training systems for workers. Technical report.

EADA Business School Barcelona and ICSA Grupo (2014). $8^{\circ}$ informe de diferencias retributivas entre sexos. Technical report.

Edralin, D. M. (2007). Human Capital Development for Innovation in Asia: Training and Development Practices and Experiences of Large Philippine Companies. Asian Journal of Technology Innovation, 15(1), 133-147.

Ellstrom, P. (2010). Practice-based innovation: a learning perspective. Journal of Workplace Learning, 22(1/2), 27-40.

European Commission (2013). SBA Fact Sheet 2013, Spain. Retrieved January 29, 2015, from, http://ec.europa.eu/enterprise/policies/sme/facts-figuresanalysis/performance-review/files/countries-sheets/2013/spain_en.pdf.

Fang, S., Chou, C., Yang, S., \& Tsai, F. (2011). Relationship learning and innovation: The role of relationship-specific memory. Industrial Marketing Management, 40(5), 743-753.

Fluellen, J.E. (2011). Creating a Nation of Innovators. Retrieved January 29, 2015, from, http://files.eric.ed.gov/fulltext/ED531063.pdf.

Fernández Nogales, A. (2004). Investigación y técnicas de mercados. Madrid: ESIC Editorial.

FTFE (2015). Formación en las empresas. Informe anual 2014. Madrid: Fundación Tripartita para la Formación en el Empleo.

Heiskanen, T., \& Heiskanen, H. (2011). Spaces of innovation: experiences from two small high-tech firms. Journal of Workplace Learning, 23(2), 97-116.

Ho, L. (2010). Meditation, learning, organizational innovation and performance. Industrial Management and Data Systems, 111(1), 113-131.

Jiménez, D., \& Sanz, R. (2008). Could HRM support organizational innovation?. The International Journal of Human Resource Management, 19(7), $1208-1221$.

Kirah, A. (2008). Innovation is for everyone. Learning is for everyone, an interview with Anna Kirah. eLearning Papers, 8.

Kontoghiorghes, C., Awbrey, S. M., \& Feurig, P. L. (2005). Examining the relationship between learning organization characteristics and change adaptation, innovation, and organizational performance. Human resource development quarterly, 16(2), 185-211.

Löfsten, H. (2014). Product innovation processes and the trade-off between product innovation performance and business performance. European Journal of Innovation Management, 17(1), 61 - 84.

Marsick, V.J., \& Watkins, K.E. (1990). Informal and incidental learning in the workplace. London and New York: Routledge.

Martínez-Ros, E., \& Orfila-Sintes, F. (2012). Training plans, manager's characteristics and innovation in the accommodation industry. International Journal of Hospitality Management, 31(3), 686-694.

Organization for Economic Co-operation and Development (2013). PIAAC database. Retrieved January 29, 2015, from,

http://www.oecd.org/site/piaac/publicdataandanalysis.htm.

Pineda, P. (coord.) (2013). Evaluación de la eficacia de la formación para la innovación. Análisis de casos de éxito. Research Report. Madrid: Fundación Tripartita para la Formación en el Empleo. Retrieved October 15, 2014, from, http://www.fundaciontripartita.org/almacenv/webpubpro/textbase/aacc02/anexos/20110373.pdf. 
Rasiah, R. (2011). Epilogue: Implications from industrializing East Asia's innovation and learning experiences. Asia Pacific Business Review, 17(2), $257-262$. Rasmussen, P. (2012). Creative and innovative competence as a task for adult education. Lifelong Learning in Europe (LLinE), 2012(4).

Ridderstrale, J., \& Nordström, K. (2008). Funky business forever. How to enjoy capitalism (3rd ed.). Harlow: Financial Times Prentice Hall.

Smith, A., Courvisanos, J., Tuck, J., \& McEachern, S. (2011). Building innovation capacity: the role of human capital formation in enterprises - a review of the literature. Adelaide: NCVER.

Soriano, D.R., \& Huarng, K.-H. (2013). Innovation and entrepreneurship in knowledge industries. Journal of business research, 66(10), 1964 -1969.

Tidd, J., Bessant, J., \& Pavitt, K. (2005). Managing Innovation: Integrating technological, market and organizational change ( 3rd ed.). New York: John Wiley \& Sons.

Tynjälä, P. (2008). Perspectives into learning at the workplace. Educational Research Review, 3, 130-154.

Yu Yuan, R., Ya-Hui, B., Yang, B., Wu, C., \& Kuo, Y. (2011). Impact of TQM and organizational learning on innovation performance in the high-tech industry. International Business Review, 20(2), 213-225. 